\title{
Pandemia por coronavirus (COVID-19); sorpresa, miedo y el buen manejo de la incertidumbre en la familia
}

\author{
Coronavirus pandemics (COVID-19): surprise, fear and successful \\ management of uncertainty within the family \\ Pandemia de coronavírus (COVID-19): surpresa, medo e o correto
manejo da incerteza na família
}

La pandemia por coronavirus (COVID-19) tuvo una llegada brutal, inesperada, que nos exigió un cambio de rumbo de todas las actividades planificadas a nivel escolar, laboral y otras tantas actividades pensadas para este año. Tuvimos que redelinear el rumbo sobre la marcha, de manera increíblemente rápida, con cambios muy profundos de hábitos, con aprendizaje, crecimiento y convivencia en un ambiente de gran incertidumbre.

Y para niños y niñas los cambios también fueron muy profundos: no asistir a escuelas y liceos, recibir clases onli$n e$, comunicación a través de plataformas digitales con sus amigos y no practicar deportes ni tener ninguna actividad comunitaria, por mencionar algunas de las situaciones nuevas que están viviendo.

Además, el aumento de las horas en sus casas lleva indefectiblemente a un aumento exponencial de estímulos audiovisuales: juegos, material de estudio, actividades recreativas e información acerca de esta pandemia. También la posibilidad de estar en conversaciones con adultos, con emociones que a veces pueden ser disparadoras de estrés, tristeza y ansiedad.

Por estas razones, hemos implementado desde la Comisión Directiva la realización de diversos módulos en base a videos, cuentos, consejos acerca del abordaje de este problema, y difusión de información útil, adecuada y real.

Como padres, es muy importante tener una conversación franca con los hijos, no minimizando su preocupación, sino buscando comprenderlos y tranquilizarlos.

Algunas de las preocupaciones más frecuentes de los niños son:

- ¿Estoy a salvo?

- ¿Están ustedes a salvo?

- ¿Cómo afectará mi vida?

- ¿Cuánto durará?

Por eso -y teniendo en cuenta que esta situación nos da la oportunidad de cambiar nuestros hábitos y tener una convivencia prolongada-, es importante volver a enfocarnos en la dinámica del día a día.

$\mathrm{Y}$ al hacerlo, algunas recomendaciones que debemos tener presentes son:

- Controlar nuestra ansiedad, dar información útil y datos reales.

- Procurar estar al día con los avisos de la escuela.

- Tener hábitos saludables, tales como horarios para dormir, comer o hacer ejercicio en casa.

- Ser honestos frente a las preguntas de los niños, por ejemplo: "Sí, estoy preocupado, pero al mismo tiempo sé que hay formas de prevenir la propagación del virus y de cuidar de nuestra familia".

- Informarse sobre qué saben y de dónde leen y escuchan, de modo tal de poder guiarlos en la búsqueda, mostrando lugares que brindan información veraz.

- Validar los sentimientos y preocupaciones de los hijos y tener una conversación con un vocabulario acorde a la edad de ellos.

- Estar disponible, porque esta será una de muchas otras situaciones en las que se sienten a conversar padres e hijos. Al finalizar la conversación, evaluar el nivel de ansiedad en base al lenguaje corporal, tono de voz, respiración, entre otras manifestaciones.

doi: 10.31134/AP.91.2.1 
- Empoderarlos y estar presentes en la modificación de su comportamiento frente a conductas de prevención (lavados de manos, tos, estornudos, mantener las manos alejadas de la cara, no saludar con las manos, no tener contacto físico, higiene, desinfección).

- Siempre es muy importante dar ejemplos con los comportamientos, de modo de que tengan un buen modelo a seguir.

- Es importante que en la medida en que realizan o lleven a cabo conductas sobre prevención de manera óptima, los elogiemos y destaquemos sus acciones. Ya que no solo se están cuidando, sino que están ayudando a prevenir la propagación de gérmenes a otros.

- Son buenos momentos para reforzar la importancia de la solidaridad, un valor muy preciado que siempre es importante adquirirlo desde la más tierna infancia.

- Es un tiempo en el que debemos demostrar lo valioso que somos todos, porque todos podemos encontrarnos y juntos enfrentar y ganar esta batalla... ique es de todos!

En definitiva, este tiempo nos deja mucho aprendizaje, crecimiento, reencuentro familiar, capacidad de cambios y de ser flexibles frente a los obstáculos. Nos ayuda a estar informados, ser creativos y, además, nos enseña a valorar el gran gesto de confianza que es el apretón de manos, ique ya regresará! Mientras tanto, una lección que nos queda es que la higiene, bien hecha y oportuna, puede salvar vidas.

Dra. Catalina Pinchak

Presidenta de la Sociedad Uruguaya de Pediatría

Montevideo, abril 2020

ORCID 0000-0001-7957-6341 